\title{
Essential fatty acid intake and serum fatty acid composition among adolescent girls in central Mozambique
}

\author{
Riitta Freese $^{1_{*}^{*}}$, Liisa Korkalo ${ }^{1}$, Bengt Vessby $^{2}$, Siv $_{\text {Tengblad }}^{2}$, Elina M. Vaara ${ }^{1} \dagger$, Helena Hauta-alus ${ }^{1} \neq$, \\ Kerry Selvester ${ }^{3}$ and Marja Mutanen ${ }^{1}$ \\ ${ }^{1}$ Division of Nutrition, Department of Food and Environmental Sciences, PO Box 66, FIN-00014 \\ University of Helsinki, Helsinki, Finland \\ ${ }^{2}$ Department of Public Health and Caring Sciences, Clinical Nutrition and Metabolism, Uppsala University, \\ Uppsala Science Park, SE-751 85 Uppsala, Sweden \\ ${ }^{3}$ Nutrition and Food Security Association (ANSA), Maputo, Mozambique
}

(Submitted 9 May 2014 - Final revision received 12 January 2015 - Accepted 16 January 2015 - First published online 16 March 2015)

\section{Abstract}

Many African diets are low in fat but are currently changing because of nutrition transition. We studied fat and fatty acid (FA) intake and the essential fatty acid (EFA) status of adolescent girls (aged 14-19 years, $n$ 262) in Zambezia Province, central Mozambique. A cross-sectional study was carried out in a city as well as in the towns and rural villages of a coastal and an inland district. Dietary intake and FA sources were studied in a $24 \mathrm{~h}$ dietary recall. FA compositions of cholesteryl esters and phospholipids of non-fasting serum samples were analysed by GLC. Fat intake was low (13-18\% of energy) in all areas. Coconut and palm oil were the main sources of fat, and soyabean oil and maize were the main sources of PUFA. Compared to Food and Agriculture Organization/WHO 2010 recommendations, intake of linoleic acid (LA, 18:2n-6) was inadequate in the coastal district, and intakes of $n$-3 PUFA were inadequate in all areas. FA compositions of serum lipids differed between areas. The proportions of LA tended to be highest in the city and lowest in the rural areas. The phospholipid mead (20:3n-9):arachidonic acid $(20: 4 n-6)$ ratio did not indicate EFA insufficiency. LA proportions in phospholipids were low, but those of long-chain $n-6$ and n-3 PUFA were high in comparison with Western adolescents. To conclude, fat sources, FA intake and EFA status differed between adolescent girls living in different types of communities. Fat intake was low, but EFA insufficiency was not indicated.

\section{Key words: Adolescent girls: Essential fatty acids: Sub-Saharan Africa}

Fatty acids are a central source of energy for the body, but they are also necessary for various structural and signalling functions. PUFA from the $n-6$ and $n-3$ families, linoleic acid (LA, 18:2n-6) and $\alpha$-linolenic acid (ALA; 18:3n-3) are essential fatty acids (EFA) and serve as precursors for functionally essential long-chain PUFA (LC-PUFA), arachidonic acid (AA, $20: 4 n-6)$, EPA (20:5n-3) and DHA (22:6n-3).

The proportions of $n-3$ and $n-6$ PUFA in cell membranes and circulating lipid fractions are modified by not only the dietary intake but also the activities of the desaturases and elongases that are needed for LC-PUFA synthesis and the enzymes that incorporate fatty acids into lipids ${ }^{(1,2)}$. Desaturase activities are modified, e.g., by genetic polymorphisms ${ }^{(3)}$ and nutritional status. Inadequate intakes of protein as well as several micronutrients decrease the activity of the rate-limiting enzyme $\Delta-6$ desaturase ${ }^{(4)}$. Furthermore, disturbed fat absorption due to inflammatory intestinal diseases or helminth infections may affect fatty acid absorption and EFA status $^{(5,6)}$. Many of these modifying factors may be relevant in low-income settings.

African diets, especially in rural areas, are often very rich in carbohydrates and low in fat. Very low intakes of fat may compromise the sufficient intake of EFA. On the other hand, an increased consumption of high-LA foods and oils (e.g. maize, peanut, safflower or sunflower oils), combined with small intakes of ALA and preformed $n-3$ LC-PUFA, could weaken the $n$ - 3 LC-PUFA status. This again could be detrimental during pregnancy, lactation and early childhood $^{(7)}$. There are major study gaps concerning fat and fatty acid intake and fatty acid status in African populations,

Abbreviations: en $\%$, percentage of energy; AA, arachidonic acid; ALA, $\alpha$-linolenic acid; EFA, essential fatty acids; LA, linoleic acid; LC-PUFA, long-chain PUFA; MA, mead acid.

*Corresponding author: Dr R. Freese, email riitta.freese@helsinki.fi

†Present address: Department of Social Research, University of Helsinki, Helsinki, Finland.

$\ddagger$ Present address: Institute of Clinical Medicine, Children’s Hospital, University of Helsinki, Helsinki, Finland. 
and more information is needed on vulnerable groups, including pregnant and lactating women as well as infants ${ }^{(7,8)}$.

Differences between rural and urban living conditions and diets may be marked in populations that are facing nutrition transition. The increased intakes of sugar, processed foods and animal products and the decreased intake of fibre-rich foods, all of which are markers of a transition from the receding famine to the degenerative disease stage, are first seen in urban areas ${ }^{(9-13)}$. Mozambique in eastern sub-Saharan Africa is at an early stage of nutrition transition ${ }^{(14)}$. Adolescent pregnancies are common in Mozambique.

We studied the intakes and dietary sources of fat and fatty acids, as well as serum fatty acid composition, in a cross-sectional sample of 262 adolescent girls in Zambezia Province, central Mozambique. Our focus was on EFA intake and status. The participants were girls from three districts, and the types of communities ranged from rural villages to neighbourhoods of the principal town in the province. We expected to find differences between diets and the fatty acid statuses of girls living in different settings. We also hypothesised that very low fat intake could be associated with compromised EFA intake and status.

\section{Subjects and methods}

\section{Subjects}

This cross-sectional study includes a subsample of the total number of 551 girls who participated in a study focusing on the diet, nutrient intakes and nutritional status of adolescent girls living in different types of communities in Zambezia Province, central Mozambique. The study was carried out in two stages: the first during the lean season and the second during the harvest season. The present sample was collected in January-February 2010 during the lean season. Girls aged 14 to 19 years (median 16 years) were studied in the principal town of Zambezia, Quelimane (city), as well as in the district towns and rural villages of the coastal Maganja da Costa district (about $140 \mathrm{~km}$ to the north-east of Quelimane) and the inland Morrumbala district (about $200 \mathrm{~km}$ to the north-west of Quelimane). The sampling and recruitment are described in detail elsewhere ${ }^{(15)}$. The majority of the population in the districts live in rural villages. Thus, the numbers studied in the district towns are smaller than those in Quelimane or those in the rural villages. The present sample includes all of the girls studied in January-February from whom we were able to collect an adequate serum sample (262 out of 284 girls).

The present study was conducted according to the guidelines laid down in the Declaration of Helsinki, and all procedures involving human subjects were approved by the National Ethical Committee at the Ministry of Health in Mozambique. Written informed consent was obtained from all of the girls and either their parent, husband or guardian. The present study has been registered at clinicaltrials.gov as NCT01944891.

\section{Background and diet}

Background data was collected by interview questionnaires. The questionnaire included questions on, e.g., education, marital status and household assets. The diet was studied through a $24 \mathrm{~h}$ dietary recall using food photographs for portion size estimation. A Mozambican food composition database was compiled for the purposes of the present study ${ }^{(16)}$, and nutrient intakes were calculated by Nutrisurvey software (update 29 October 2007) ${ }^{(17)}$.

Weight and height were measured by standardised methods ${ }^{(18)}$. $Z$ scores for BMI and height were calculated with the SPSS macro provided by the WHO (WHO Reference 2007 SPSS macro package $)^{(19)}$. The cut-offs for overweight and thinness were a BMI-for-age $z$ score of $\geq 1$ and $\leq-2$, respectively ${ }^{(19,20)}$. A girl was classified as moderately or severely stunted (chronic undernutrition) if her height-for-age $z$ score was -2 or less

\section{Blood sampling and laboratory measurements}

Non-fasting venous blood samples were drawn from the antecubital vein in the laboratory of the health centre or hospital by local laboratory technicians. The samples were taken with $21 \mathrm{~g}$ needles in plastic serum $(10 \mathrm{ml})$ and $\mathrm{K}_{3}$ EDTA $(3 \mathrm{ml})$ tubes (BD Vacutainer ${ }^{\circledR} ;$ Becton Dickinson International). Blood samples were processed on site. The serum tubes were allowed to stand at room temperature $\left(22-36^{\circ} \mathrm{C}\right)$ for $30 \mathrm{~min}$ before centrifugation (Labnet spectrafuge 6C; Labnet International) at $4500 \mathrm{rpm}$ for $10 \mathrm{~min}$ at room temperature. Aliquots of serum were frozen at $-20^{\circ} \mathrm{C}$ in the laboratory and transported to Maputo by car in a portable freezer $\left(-15^{\circ} \mathrm{C}\right)$. In Maputo, they were packed in dry ice and shipped to Finland, where they were stored at $-70^{\circ} \mathrm{C}$. The maximum time for storage at $-20^{\circ} \mathrm{C}$ was 2 months.

Before blood sampling, the local laboratory technician asked each girl whether she consented to the blood sampling and the testing for HIV, malaria and pregnancy. The laboratory technicians performed one-step malaria (Plasmodium falciparum) tests (SD Bioline Malaria Ag P.f., Standard Diagnostics) and HIV tests (Determine ${ }^{\circledR}$ HIV-1/2; Inverness Medical Japan and Uni-Gold $^{\mathrm{TM}} \mathrm{HIV}$; Trinity Biotech if needed for confirmation) from EDTA blood samples. They also performed pregnancy tests (Insight-HCG; Tulip Diagnostics or Onsite HCG Combo Rapid Test; CTK Biotech) from spot urine samples and examined stool samples for intestinal helminths under microscope by direct faecal smear exam. Permissions for HIV antibody and pregnancy tests were given by $70 \%$ of the girls. Almost all girls (96\%) consented to malaria tests. Faecal samples were provided by $63 \%$ of the girls. Pregnancy was defined as having a positive urine test result or being visibly pregnant (four untested girls). A girl was classified as non-pregnant if the urine test result was negative or, when test results were not available, if she had reported herself 'not pregnant' in the background interview.

Serum total cholesterol and TAG were analysed at the Disease Risk Unit of the National Institute for Health and Welfare, Finland, with automated analyser (Architect ci8200 analyser; Abbott Diagnostics).

\section{Fatty acid analyses}

Fatty acid analyses were carried out at the Department of Public Health and Caring Sciences, Uppsala University, Sweden. 
Serum cholesteryl ester and phospholipid fractions were separated by TLC, and fatty acid composition was measured by GLC on a $30 \mathrm{~m}$ glass capillary column coated with Thermo TR-FAME (Thermo Electron Corporation) ${ }^{(21)}$. The CV between successive GLC runs ranged from 0.5 to $5 \%$, with the exception of $15: 0$ and $18: 0$ in the cholesteryl esters, which had a CV between 5 and $10 \%$. The relative amounts of fatty acids were expressed as percentages of the total amount of fatty acids reported $(\mathrm{w} / \mathrm{w} \%$ of the total fatty acids). The ratio of the proportions of mead acid (MA, 20: $3 n-9)$ to AA in phospholipids (triene:tetraene ratio, or Holman index $)^{(22)}$ was calculated as a marker of EFA status. The rationale for the index is that notable formation of MA from 18:1n-9 occurs only when the intakes of both LA and ALA are inadequate. A phospholipid MA:AA ratio larger than $0 \cdot 2^{(23)}$ was used as the biochemical marker of EFA insufficiency. Such values have been reported in serum phospholipids of fat malabsorption patients ${ }^{(5,24,25)}$. The ratio of phospholipid AA to DHA was calculated to compare the proportions of $n-6$ and $n-3$ LC-PUFA.

\section{Statistical analysis}

All statistical analyses were performed using the PASW Statistic 18 for Windows software or IBM SPSS version 21 for Mac (SPSS, Inc.). The results were expressed as medians and interquartile ranges or means and standard deviations; and categorical data were expressed as percentages and frequencies.

Depending on the normality of the variable, a one-way ANOVA and Tukey test or a non-parametric Kruskal-Wallis one-way ANOVA and Mann-Whitney $U$ test were used to compare the data between the areas. Because pregnancy modifies EFA status ${ }^{(26,27)}$, statistical comparisons between fatty acid compositions in different areas were also carried out excluding the pregnant girls. Furthermore, comparisons between groups divided by malaria status in rural Maganja da Costa and helminth status in Quelimane were carried out with an independent samples $t$ test or a Mann-Whitney $U$ test. In all analyses, $P$ values smaller than 0.05 were considered to be statistically significant.

The contributions of different foods to the intake of energy, fat and fatty acids were assessed by calculating population proportions ${ }^{(28)}$ from the $24 \mathrm{~h}$ dietary recall data.

\section{Results}

\section{Background characteristics}

Most of the girls were within normal weight range (Table 1). Overweight girls were found in the city of Quelimane ( $n$ 11, $13.4 \%$ ) and the district town of Morrumbala ( $n$ 3, 13.6\%). Four girls in the rural areas were classified as thin ( $n 1$ in rural Maganja da Costa and $n 3$ in rural Morrumbala). The proportions of girls categorised as moderately or severely stunted were $9.8 \%$ in Quelimane, $22.2 \%$ in Maganja da Costa district town, $15.0 \%$ in rural Maganja da Costa, $13.6 \%$ in Morrumbala district town and $22.7 \%$ in rural Morrumbala.

In the majority of rural households $(74 \%$ in Maganja da Costa, $80 \%$ in Morrumbala), the head of the household was occupied in farming or fishing. In the district towns of Maganja da Costa and Morrumbala and in the city of Quelimane, farming or fishing was the occupation of the household

Table 1. Background characteristics of the adolescent girls ( $n$ 262) in five study areas in central Mozambique (Mean values and standard deviations; number of girls and percentages)

\begin{tabular}{|c|c|c|c|c|c|c|c|c|c|c|}
\hline \multirow[b]{3}{*}{ Variable } & & & \multicolumn{4}{|c|}{ Maganja da Costa } & \multicolumn{4}{|c|}{ Morrumbala } \\
\hline & \multicolumn{2}{|c|}{$\begin{array}{l}\text { Quelimane } \\
\text { (n 83) }\end{array}$} & \multicolumn{2}{|c|}{$\begin{array}{l}\text { District town } \\
\quad(n 18)\end{array}$} & \multicolumn{2}{|c|}{$\begin{array}{l}\text { Rural villages } \\
\qquad(n 73)\end{array}$} & \multicolumn{2}{|c|}{$\begin{array}{l}\text { District town } \\
\qquad(n 22)\end{array}$} & \multicolumn{2}{|c|}{$\begin{array}{l}\text { Rural villages } \\
\qquad(n 66)\end{array}$} \\
\hline & Mean & SD & Mean & SD & Mean & SD & Mean & SD & Mean & SD \\
\hline Age (years) & $16 \cdot 2$ & $1 \cdot 3$ & $16 \cdot 6$ & 0.9 & $16 \cdot 3$ & $1 \cdot 3$ & $15 \cdot 8$ & $1 \cdot 2$ & $15 \cdot 8$ & $1 \cdot 1$ \\
\hline $\mathrm{BMI}^{*}\left(\mathrm{~kg} / \mathrm{m}^{2}\right)$ & $21 \cdot 1$ & $2 \cdot 7$ & $20 \cdot 1$ & $1 \cdot 7$ & $20 \cdot 0$ & $2 \cdot 2$ & $21 \cdot 3$ & 2.5 & $19 \cdot 5$ & 1.9 \\
\hline 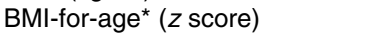 & -0.03 & 0.84 & -0.35 & 0.62 & -0.41 & 0.91 & 0.13 & 0.81 & -0.51 & 0.76 \\
\hline Height-for-age ( $z$ score) & -0.94 & 0.85 & -1.35 & 0.62 & $-1 \cdot 35$ & 0.62 & -1.22 & 0.80 & -1.44 & 0.93 \\
\hline Serum total cholesterol $(\mathrm{mmol} / \mathrm{l})$ & $4 \cdot 30$ & 0.75 & 3.99 & 0.62 & $3 \cdot 91$ & 0.73 & 3.66 & 0.72 & 3.25 & 0.68 \\
\hline \multirow[t]{2}{*}{ Serum TAG $(\mathrm{mmol} / \mathrm{l})$} & 0.93 & 0.36 & 1.03 & 0.33 & $1 \cdot 14$ & 0.43 & 0.97 & 0.40 & 1.03 & 0.42 \\
\hline & $\%$ & $n$ & $\%$ & $n$ & $\%$ & $n$ & $\%$ & $n$ & $\%$ & $n$ \\
\hline Literate† & $87 \cdot 8$ & 72 & $62 \cdot 5$ & 10 & $34 \cdot 3$ & 24 & $38 \cdot 1$ & 8 & $12 \cdot 5$ & 8 \\
\hline Has given birth & $17 \cdot 1$ & 14 & $17 \cdot 6$ & 3 & $16 \cdot 4$ & 12 & $18 \cdot 2$ & 4 & $20 \cdot 0$ & 13 \\
\hline \multirow[t]{2}{*}{ Pregnant } & 8.5 & 7 & $5 \cdot 6$ & 1 & $18 \cdot 3$ & 13 & 4.5 & 1 & $15 \cdot 2$ & 10 \\
\hline & $\%$ & $n / N$ & $\%$ & $n / N$ & $\%$ & $n / N$ & $\%$ & $n / N$ & $\%$ & $n / N$ \\
\hline HIV positiveł & 11.6 & $5 / 43$ & $6 \cdot 3$ & $1 / 16$ & $6 \cdot 7$ & $3 / 45$ & $6 \cdot 7$ & $1 / 15$ & $3 \cdot 1$ & $2 / 65$ \\
\hline Malariał & $1 \cdot 3$ & $1 / 77$ & $11 \cdot 1$ & $2 / 18$ & $30 \cdot 4$ & $21 / 69$ & $4 \cdot 5$ & $1 / 22$ & 0 & $0 / 66$ \\
\hline Intestinal helminthsł & $28 \cdot 6$ & $12 / 42$ & 0 & $0 / 15$ & $12 \cdot 0$ & $6 / 50$ & 5.9 & $1 / 17$ & $22 \cdot 0$ & $9 / 41$ \\
\hline
\end{tabular}

* Only non-pregnant girls are included ( $n$ 229).

†The girl is able to read a test sentence written in Portuguese.

$\ddagger$ Tests were performed if the girl allowed; values are \% ( $n /$ total number of compliant girls). 
head in 50, 32 and $16 \%$ of households, respectively. The literacy rate of the girls varied from $88 \%$ in Quelimane to $13 \%$ in rural Morrumbala (Table 1). Rural girls were more often married or pregnant than girls living in urban environments. In all areas, 16 to $20 \%$ of the girls had given birth.

Malaria was frequent only in rural Maganja da Costa. Helminths were most prevalent in Quelimane and rural Morrumbala (Table 1). The proportion of girls who tested as HIV positive was the largest in Quelimane and the smallest in rural Morrumbala.

\section{Diet}

The median energy $(4 \cdot 1-6 \cdot 8 \mathrm{MJ} / \mathrm{d})$ and fat (13-18\% of energy, en\%) intakes were low (Table 2). Carbohydrates were the most important source of energy in all areas, providing 68 to 76 en $\%$. The median intake of PUFA ranged from 1.2 to 3.4 en $\%$. LA intake was the lowest in rural Maganja da Costa, and intake of $n$-3 LC-PUFA was the lowest in the Morrumbala district.

Maize, rice, cassava and mango were the most important sources of carbohydrates and energy (Table 3). The main staple foods were rice and maize in Quelimane, cassava and rice in Maganja da Costa and maize and rice in Morrumbala. Mango provided about one-third of energy in the Maganja da Costa district during the study period. Coconut and palm oil were the most important sources of fat and SFA in all areas except for rural Morrumbala, where maize provided 20\% of total fat. However, palm oil was also a main source of SFA in rural Morrumbala (Table 3). Soyabean oil and maize were the main sources of PUFA and LA. Mango and soyabean oil provided most of the ALA in all areas, and maize was also a main source of ALA in rural Morrumbala. Fish and shellfish provided noticeable amounts of PUFA in Quelimane and the Maganja da Costa district, while meat and poultry were marked sources of fat and fatty acids only in rural Morrumbala.

\section{Fatty acids}

Differences were found in the proportions of all fatty acids between the study areas. Serum cholesteryl esters (Table 4) and phospholipids (Table 5) mainly reflected similar differences. The girls living in Quelimane had the highest proportion of LA and the lowest proportions of ALA and MA in their serum lipids. The phospholipid MA:AA ratio was also lowest in this group. In comparison to Quelimane, the fatty acid compositions of the girls living in rural Maganja da Costa were mostly on the other end of the distribution. The lowest proportion of LA and the highest proportion of ALA in serum lipids characterised these girls. The proportion of MA was high in comparison to other areas, and the MA:AA ratio was highest in rural Maganja da Costa. Rural Morrumbala was another area with low LA and high MA proportions in serum lipids. In that area, the proportions of EPA and DHA were the lowest, and the proportion of AA was the highest. The phospholipid AA:DHA ratio was highest in rural Morrumbala. The fatty acid profiles of the girls living in the district towns stood, in most cases, between the profiles of the girls living in the respective rural areas and Quelimane.
Phospholipid MA:AA ratios ranged from 0.007 to 0.192 (Table 5). None of the girls had a ratio of more than $0 \cdot 2$.

The statistical comparisons were repeated using only the data from non-pregnant girls. There were some alterations in the post hoc comparisons (for example, in the differences between rural villages and their respective district towns), but the main conclusions remained unaltered. For instance, phospholipid LA, AA, DHA, MA and AA:DHA ratio showed exactly the same patterns of significant differences between areas as those indicated in Table 4 (data not shown).

Comparisons between malaria-positive and malarianegative girls in rural Maganja da Costa showed significant differences in cholesteryl ester 16:0,17:0 and 18:0 and phospholipid 20:3n-6 (the proportions were higher in the malaria-positive group). Comparisons between groups divided by helminth status in Quelimane indicated no significant differences.

\section{Discussion}

The present results show that the sources and intake of EFA as well as serum fatty acid compositions differed between adolescent girls living in different types of communities in central Mozambique. Fat and EFA intakes were generally low. Serum phospholipid MA:AA ratio did not, however, indicate the presence of biochemical EFA insufficiency.

The Food and Agriculture Organization (FAO)/WHO ${ }^{(29)}$ recommends that fat intake should be at least $20 \mathrm{en} \%$ for women of reproductive age, especially in developing countries, to ensure sufficient amounts of EFA. In the present study, most of the adolescent females had lower-than-recommended fat intake. Furthermore, coconut and palm oil, which are both high in SFA and low in EFA, were the main sources of fat. The median intakes of total PUFA and LA were below the acceptable intakes $(2.5-3.5 \text { and } 2-3 \text { en } \% \text {, respectively })^{(29)}$ in the Maganja da Costa district. The median intake of ALA did not reach the lower end of the acceptable macronutrient distribution range $(0.5 \mathrm{en} \%)$ in any area. Furthermore, the median EPA + DHA intakes were below the 0.25 or $0.3 \mathrm{~g} / \mathrm{d}$ that are recommended ${ }^{(29)}$ for adult non-pregnant/non-lactating and pregnant/lactating females, respectively. Our anticipation that EFA intake would be compromised in this population appears justified. Our results are in line with the calculations of Michaelsen et al. ${ }^{(8)}$, who used FAO food balance sheets from four low-income sub-Saharan African countries (Malawi, Ethiopia, Ghana and Burkina Faso) and found that total fat availability in three out of the four countries was less than 20 en\%. n-6 PUFA supply was adequate, but in all four countries, $n$-3 PUFA supply was below the lower end of the acceptable macronutrient distribution range ${ }^{(8)}$

The areas in the present study differed from each other in many ways. The rural communities had the highest burden of stunting, illiteracy and early marriages and pregnancies, while overweight was seen only in more urban settings, and HIV and helminths were most prevalent among girls living in the city of Quelimane. These background characteristics could explain some of the differences in serum fatty acid compositions that were seen between the study areas ${ }^{(6,27,30)}$. However, we have no indication that pregnancy, helminth 
Table 2. Calculated energy, macronutrient and fatty acid intakes of the adolescent girls ( $n$ 259) in five study areas in central Mozambique* (Medians and 25th-75th percentiles)

\begin{tabular}{|c|c|c|c|c|c|c|c|c|c|c|c|}
\hline \multirow[b]{3}{*}{ Nutrient } & & & \multicolumn{4}{|c|}{ Maganja da Costa } & \multicolumn{4}{|c|}{ Morrumbala } & \multirow[b]{3}{*}{$P \neq$} \\
\hline & \multicolumn{2}{|c|}{ Quelimane $(n$ 82) $\dagger$} & \multicolumn{2}{|c|}{ District town ( $n$ 18) } & \multicolumn{2}{|c|}{ Rural villages ( $n 71)$} & \multicolumn{2}{|c|}{ District town ( $n$ 22) } & \multicolumn{2}{|c|}{ Rural villages ( $n 66$ ) } & \\
\hline & Median & $\begin{array}{l}\text { 25th-75th } \\
\text { percentile }\end{array}$ & Median & $\begin{array}{l}\text { 25th-75th } \\
\text { percentile }\end{array}$ & Median & $\begin{array}{l}\text { 25th-75th } \\
\text { percentile }\end{array}$ & Median & $\begin{array}{l}\text { 25th-75th } \\
\text { percentile }\end{array}$ & Median & $\begin{array}{l}\text { 25th-75th } \\
\text { percentile }\end{array}$ & \\
\hline Energy $(\mathrm{MJ} / \mathrm{d})$ & $5 \cdot 77^{\mathrm{b}}$ & $4 \cdot 22-7 \cdot 25$ & $4.99^{a, b}$ & $3.67-9.41$ & $5 \cdot 31^{\mathrm{b}}$ & $3.62-7.29$ & $6.75^{\mathrm{b}}$ & $4.57-9.25$ & $4.08^{a}$ & $3.09-5.83$ & 0.001 \\
\hline Protein (en\%) & $10 \cdot 3^{b}$ & $8 \cdot 8-12 \cdot 0$ & $7 \cdot 6^{\mathrm{a}}$ & $6 \cdot 2-10 \cdot 1$ & $7 \cdot 2^{\mathrm{a}}$ & $6.1-8.6$ & $9 \cdot 6^{\mathrm{b}}$ & $7 \cdot 6-10 \cdot 9$ & $10 \cdot 8^{\mathrm{b}}$ & $9 \cdot 1-13 \cdot 1$ & $<0.001$ \\
\hline Carbohydrate (en\%) & $67 \cdot 9^{a}$ & $62 \cdot 8-75 \cdot 2$ & $76 \cdot 2^{\mathrm{b}}$ & $67.4-78.7$ & $72 \cdot 0^{\mathrm{b}}$ & $64.9-78.0$ & $73 \cdot 3^{b}$ & $69 \cdot 5-77 \cdot 2$ & $73 \cdot 0^{\mathrm{b}}$ & $65 \cdot 6-78 \cdot 8$ & 0.032 \\
\hline Fat (en\%) & $18 \cdot 0^{\mathrm{c}}$ & $12 \cdot 3-23 \cdot 0$ & $14 \cdot 2^{a, b, c}$ & $8 \cdot 6-19 \cdot 7$ & $16 \cdot 4^{b, c}$ & $11 \cdot 3-23 \cdot 6$ & $14 \cdot 7^{\mathrm{a}, \mathrm{b}}$ & $11 \cdot 0-17 \cdot 0$ & $12 \cdot 8^{\mathrm{a}}$ & $7 \cdot 7-19 \cdot 8$ & 0.004 \\
\hline \multicolumn{12}{|l|}{ Fatty acids } \\
\hline SFA (en\%) & $7 \cdot 24^{\mathrm{b}}$ & $4.61-9.57$ & $6 \cdot 71^{b, c}$ & $3.42-9.67$ & $8.95^{\mathrm{c}}$ & $5.92-12.52$ & $5 \cdot 81^{b}$ & $4.77-8.74$ & $3 \cdot 64^{a}$ & $1 \cdot 39-6 \cdot 29$ & $<0.001$ \\
\hline MUFA (en\%) & $4.40^{\mathrm{b}}$ & $2 \cdot 76-6.43$ & $2 \cdot 39^{\mathrm{a}}$ & $1.85-4.73$ & $2.55^{\mathrm{a}}$ & $1.22-4.31$ & $3 \cdot 28^{a, b}$ & $2 \cdot 17-4 \cdot 47$ & $3 \cdot 48^{a, b}$ & $1.91-6.22$ & 0.002 \\
\hline \multicolumn{12}{|l|}{ LA } \\
\hline en\% & $2 \cdot 82^{\mathrm{C}}$ & $1.79-4.46$ & $1.69^{a, b}$ & $1.08-3.08$ & $0.95^{\mathrm{a}}$ & $0.49-2.17$ & $2 \cdot 62^{b, c}$ & $1.47-3.70$ & $3.05^{c}$ & $1.95-3.98$ & $<0.001$ \\
\hline $\mathrm{g} / \mathrm{d}$ & $4 \cdot 15^{\mathrm{c}}$ & $2.45-7.83$ & $2 \cdot 82^{\mathrm{b}}$ & $1 \cdot 38-4 \cdot 31$ & $1.22^{\mathrm{a}}$ & $0.64-3.46$ & $3 \cdot 61^{b, c}$ & $2 \cdot 74-6 \cdot 20$ & $3 \cdot 24^{\mathrm{b}}$ & $2 \cdot 19-5 \cdot 11$ & $<0.001$ \\
\hline \multicolumn{12}{|l|}{ ALA } \\
\hline en $\%$ & 0.19 & $0.14-0.49$ & 0.22 & $0.16-0.39$ & 0.18 & $0.13-0.25$ & 0.19 & $0.16-0.33$ & 0.22 & $0.13-0.32$ & 0.440 \\
\hline $\mathrm{g} / \mathrm{d}$ & $0.35^{\mathrm{b}}$ & $0.16-0.72$ & $0.41^{a, b}$ & $0.17-0.58$ & $0.24^{a, b}$ & $0.14-0.53$ & $0.40^{\mathrm{b}}$ & $0.26-0.57$ & $0.23^{a, b}$ & $0.13-0.48$ & 0.013 \\
\hline \multicolumn{12}{|l|}{$n-3$ LC-PUFA } \\
\hline en $\%$ & $0.16^{\mathrm{c}}$ & $0.05-0.39$ & $0.21^{b, c}$ & $0.05-0.28$ & $0.09^{\mathrm{b}}$ & $0.04-0.18$ & $0.04^{\mathrm{a}}$ & $0.01-0.09$ & $0.05^{\mathrm{a}}$ & $0-0.13$ & $<0.001$ \\
\hline$g / d$ & $0.23^{c}$ & $0.09-0.55$ & $0 \cdot 22^{b, c}$ & $0.11-0.56$ & $0.13^{\mathrm{b}}$ & $0.05-0.29$ & $0.08^{a}$ & $0.02-0.12$ & $0.06^{a}$ & $0-0 \cdot 16$ & $<0.001$ \\
\hline LA:ALA & $10 \cdot 7^{b}$ & $8 \cdot 1-16 \cdot 8$ & $8 \cdot 0^{\mathrm{a}}$ & $5.4-10 \cdot 6$ & $5 \cdot 9^{\mathrm{a}}$ & $3.4-9.4$ & $10 \cdot 1^{\mathrm{b}}$ & $7 \cdot 8-16 \cdot 1$ & $13 \cdot 1^{\mathrm{b}}$ & $9 \cdot 1-20 \cdot 7$ & $<0.001$ \\
\hline
\end{tabular}

en\%, percentage of energy; LA, undifferentiated $18: 2$ fatty acids; ALA, undifferentiated $18: 3$ fatty acids; $n-3$ LC-PUFA, sum of $20: 5,22: 5$ and $22: 6$.

${ }^{a, b, c}$ Median values within a row with unlike superscript letters were significantly different $(P<0.05$; Kruskal-Wallis one-way ANOVA and Mann-Whitney $U$ test $)$

* Data were calculated from $24 \mathrm{~h}$ dietary recalls.

$\pm P$ value of Kruskal-Wallis one-way ANOVA. 
Table 3. Main dietary sources of energy, fat and fatty acids in five study areas in central Mozambique*

\begin{tabular}{|c|c|c|c|c|c|}
\hline \multirow[b]{2}{*}{$\begin{array}{l}\text { Most important sources } \\
\text { of energy/nutrient† }\end{array}$} & \multirow[b]{2}{*}{$\begin{array}{l}\text { Quelimane } \\
\quad(n \text { 82) }\end{array}$} & \multicolumn{2}{|c|}{ Maganja da Costa } & \multicolumn{2}{|c|}{ Morrumbala } \\
\hline & & $\begin{array}{l}\text { District town } \\
\quad(n 18)\end{array}$ & $\begin{array}{l}\text { Rural villages } \\
\qquad(n 71)\end{array}$ & $\begin{array}{l}\text { District town } \\
\quad(n \text { 22) }\end{array}$ & $\begin{array}{l}\text { Rural villages } \\
\qquad(n 66)\end{array}$ \\
\hline \multicolumn{6}{|l|}{ Energy } \\
\hline Mango & $10 \cdot 3$ & $35 \cdot 6$ & 29.9 & 17.4 & $19 \cdot 0$ \\
\hline Maize & $15 \cdot 1$ & $6 \cdot 6$ & 4.0 & $20 \cdot 0$ & 35.4 \\
\hline Rice & $22 \cdot 3$ & $12 \cdot 7$ & $12 \cdot 1$ & $11 \cdot 2$ & 2.5 \\
\hline Cassava & 0.9 & $7 \cdot 8$ & $19 \cdot 2$ & $2 \cdot 4$ & $6 \cdot 4$ \\
\hline Sweet potato & $4 \cdot 1$ & $10 \cdot 5$ & 5.5 & 8.5 & 4.8 \\
\hline Coconut & $5 \cdot 2$ & $7 \cdot 3$ & 9.9 & $4 \cdot 1$ & 3.0 \\
\hline \multicolumn{6}{|l|}{ Fat } \\
\hline Coconut & $22 \cdot 5$ & 39.9 & 48.4 & $22 \cdot 9$ & $16 \cdot 5$ \\
\hline Palm oil & $15 \cdot 3$ & 14.5 & 14.9 & $22 \cdot 1$ & $22 \cdot 3$ \\
\hline Maize & $6 \cdot 7$ & 3.7 & $2 \cdot 0$ & 11.9 & $19 \cdot 9$ \\
\hline Meat, poultry & $4 \cdot 7$ & 0.0 & $3 \cdot 2$ & $5 \cdot 8$ & 14.3 \\
\hline \multirow{2}{*}{\multicolumn{6}{|c|}{ SFA }} \\
\hline & & & & & \\
\hline Coconut & $45 \cdot 2$ & 63.2 & $72 \cdot 3$ & 44.2 & $36 \cdot 8$ \\
\hline Palm oil & 17.9 & 13.4 & $13 \cdot 0$ & $25 \cdot 4$ & 28.6 \\
\hline Meat, poultry & $3 \cdot 7$ & 0.0 & 1.6 & 3.9 & $10 \cdot 8$ \\
\hline Margarine, butter & $9 \cdot 8$ & 8.5 & 1.5 & $6 \cdot 8$ & 1.0 \\
\hline \multicolumn{6}{|l|}{ PUFA } \\
\hline Soyabean oil & $36 \cdot 3$ & 38.9 & $38 \cdot 3$ & $21 \cdot 3$ & 13.4 \\
\hline Maize & 14.0 & $10 \cdot 7$ & $6 \cdot 6$ & $26 \cdot 2$ & 38.9 \\
\hline Meat, poultry & 2.9 & 0.0 & $5 \cdot 3$ & $5 \cdot 0$ & $12 \cdot 9$ \\
\hline Palm oil & $6 \cdot 7$ & $8 \cdot 8$ & $10 \cdot 0$ & $10 \cdot 1$ & $9 \cdot 0$ \\
\hline Fish, shellfish & $7 \cdot 4$ & 9.8 & 8.0 & 2.6 & $3 \cdot 3$ \\
\hline \multicolumn{6}{|l|}{ LA } \\
\hline Soyabean oil & $37 \cdot 8$ & $43 \cdot 3$ & 41.9 & $21 \cdot 4$ & $13 \cdot 3$ \\
\hline Maize & $16 \cdot 0$ & $13 \cdot 1$ & 7.9 & 28.9 & $42 \cdot 7$ \\
\hline Meat, poultry & $2 \cdot 8$ & 0.0 & $5 \cdot 6$ & 4.6 & $12 \cdot 6$ \\
\hline Palm oil & $7 \cdot 7$ & $10 \cdot 9$ & $12 \cdot 1$ & $11 \cdot 3$ & $10 \cdot 0$ \\
\hline \multicolumn{6}{|l|}{ ALA } \\
\hline Soyabean oil & 53.4 & $39 \cdot 3$ & 38.9 & $28 \cdot 3$ & $21 \cdot 1$ \\
\hline Mango & 9.9 & 41.9 & 33.0 & 22.6 & 24.2 \\
\hline Maize & $5 \cdot 3$ & $2 \cdot 8$ & $1 \cdot 7$ & 8.9 & $15 \cdot 7$ \\
\hline
\end{tabular}

LA, undifferentiated 18:2 fatty acids; ALA, undifferentiated 18:3 fatty acids.

* The values indicate the population proportions (\%) of energy, fat or fatty acids provided by the source calculated from $24 \mathrm{~h}$ dietary recall data. † Food sources providing at least $10 \%$ of the nutrient in at least one of the areas are listed.

infestation or the presence of malaria antigens markedly modified the results. Thus, the different serum fatty acid profiles are most probably the result of dietary differences between the study areas.

The samples from the district towns are small, and more emphasis should therefore be put on dietary and fatty acid data collected in Quelimane and the rural villages of Maganja da Costa and Morrumbala. These three areas have their own characteristics.

The most important energy sources for girls living in rural Maganja da Costa were mango (which is only available for 2-3 months per year as a main energy source) and cassava. Coconut provided $48 \%$ of fat. All of these foods are low in PUFA. Consequently, median intakes of total PUFA and LA were below the acceptable intake. Girls living in rural Maganja da Costa also had the lowest LA proportions and the highest MA:AA ratios in serum lipids. Nevertheless, the phospholipid MA:AA ratios did not exceed the cut-off value of $0 \cdot 2$, which indicates that there was no biochemical EFA insufficiency. The intake of LA that is needed to prevent EFA deficiency is very small: about $1 \mathrm{en} \%{ }^{(22,29)}$ or, if ALA intake is adequate, possibly even less ${ }^{(31)}$. Apparently, the intake of EFA even in rural Maganja da Costa was enough to prevent biochemical insufficiency. However, seeing as there were some high MA:AA ratios, we suppose that some girls could benefit from increased EFA intake, at least during the lean season. This could be achieved, for example, if some soyabean oil or another oil containing both LA and ALA was added to the diet. EFA intake would also be increased if maize (a source of LA) and ALA-rich traditional green vegetables ${ }^{(32)}$ replaced some of the cassava in the diet.

The phospholipid ratio of AA to DHA, an indicator of the $n$-6:n-3 LC-PUFA ratio, was the highest among girls living in rural Morrumbala. The low serum lipid proportions of EPA and DHA in this inland area, as compared to those in other areas, probably reflected lower intakes of $n$-3 LC-PUFA. However, we also noticed that the dietary LA:ALA intake ratio was highest in rural Morrumbala. Excessive LA intake combined with limited intake of $n$-3 PUFA may weaken $n$-3 LC-PUFA status by decreasing the desaturation of ALA and reducing the incorporation of EPA and DHA into phospholipids ${ }^{(33)}$. Maize was a major source of energy and fat in rural Morrumbala, and the median intake of LA met the acceptable intake. However, the proportion of LA in serum lipids was comparatively low, while that of $n$ - 6 LC-PUFA was high. These results suggest that LA was efficiently desaturated and elongated in the girls living 
Table 4. Plasma cholesteryl ester fatty acid compositions (\%, w/w) of adolescent girls $(n 262)$ in five study areas in central Mozambique (Mean values, standard deviations and ranges)

\begin{tabular}{|c|c|c|c|c|c|c|c|c|c|c|c|}
\hline \multirow[b]{3}{*}{ Fatty acid } & & & \multicolumn{4}{|c|}{ Maganja da Costa } & \multicolumn{4}{|c|}{ Morrumbala } & \multirow{3}{*}{$\begin{array}{c}\text { All (n 262) } \\
\text { Range }\end{array}$} \\
\hline & \multicolumn{2}{|c|}{ Quelimane ( $n$ 83) } & \multicolumn{2}{|c|}{ District town ( $n$ 18) } & \multicolumn{2}{|c|}{$\begin{array}{l}\text { Rural villages } \\
\qquad(n 73)\end{array}$} & \multicolumn{2}{|c|}{$\begin{array}{l}\text { District town } \\
\quad(\text { n 22) }\end{array}$} & \multicolumn{2}{|c|}{$\begin{array}{l}\text { Rural villages } \\
\qquad(n 66)\end{array}$} & \\
\hline & Mean & SD & Mean & SD & Mean & SD & Mean & SD & Mean & SD & \\
\hline $12: 0$ & $0 \cdot 14^{\mathrm{c}}$ & 0.08 & $0.22^{d}$ & 0.09 & $0.24^{d}$ & $0 \cdot 12$ & $0.09^{b}$ & 0.05 & $0.04^{a}$ & 0.05 & $0.01-0.65$ \\
\hline $14: 0$ & $1.31^{\mathrm{C}}$ & 0.50 & $1.99^{d}$ & 0.61 & $1.94^{d}$ & 0.63 & $1.00^{\mathrm{b}}$ & 0.27 & $0.79^{a}$ & 0.24 & $0.39-3.87$ \\
\hline $15: 0$ & $0 \cdot 17^{\mathrm{a}}$ & 0.04 & $0.21^{\mathrm{b}}$ & 0.06 & $0.25^{\mathrm{c}}$ & 0.04 & $0 \cdot 23^{\mathrm{b}, \mathrm{c}}$ & 0.04 & $0.25^{c}$ & 0.06 & $0.11-0.51$ \\
\hline $16: 0$ & $13 \cdot 28^{a}$ & 0.98 & $13 \cdot 27^{\mathrm{a}}$ & 1.19 & $14.25^{\mathrm{b}}$ & 1.05 & $13 \cdot 68^{a, b}$ & 1.04 & $14 \cdot 18^{\mathrm{b}}$ & 1.02 & $10 \cdot 93-17 \cdot 24$ \\
\hline $17: 0$ & $0.08^{\mathrm{a}}$ & 0.02 & $0.09^{\mathrm{a}}$ & 0.03 & $0 \cdot 11^{\mathrm{b}}$ & 0.03 & $0 \cdot 12^{\mathrm{b}}$ & 0.02 & $0.14^{\mathrm{C}}$ & 0.03 & $0.04-0.21$ \\
\hline $18: 0$ & $0.66^{a}$ & 0.12 & $0.77^{\mathrm{b}}$ & 0.17 & $0.79^{b}$ & 0.20 & $0.77^{\mathrm{b}}$ & 0.16 & $0.75^{\mathrm{b}}$ & 0.15 & $0.36-1.85$ \\
\hline $14: 1$ & $0.03^{\mathrm{a}}$ & 0.02 & $0.05^{\mathrm{b}}$ & 0.02 & $0.07^{c}$ & 0.03 & $0.04^{\mathrm{b}}$ & 0.01 & $0.04^{\mathrm{b}}$ & 0.03 & $0.005^{*}-0.17$ \\
\hline $16: 1 n-7$ & $3.52^{\mathrm{a}}$ & 1.33 & $4 \cdot 92^{\mathrm{b}}$ & 1.86 & $7.55^{c}$ & $2 \cdot 24$ & $4.66^{\mathrm{b}}$ & 1.08 & $5.48^{\mathrm{b}}$ & 1.85 & $1.46-13.64$ \\
\hline $18: 1$ & $19 \cdot 02^{\mathrm{a}}$ & 2.02 & $20 \cdot 70^{\mathrm{a}, \mathrm{b}}$ & $2 \cdot 13$ & $23.93^{\mathrm{C}}$ & 2.82 & $21 \cdot 22^{b}$ & 1.84 & $22.91^{\mathrm{c}}$ & 3.02 & $14.56-32.52$ \\
\hline $20: 3 n-9$ & $0.06^{\mathrm{a}}$ & 0.06 & $0.13^{\mathrm{b}}$ & 0.08 & $0.24^{d}$ & $0 \cdot 10$ & $0.16^{c}$ & 0.04 & $0.23^{d}$ & 0.13 & $0.005^{\star}-0.95$ \\
\hline $18: 2 n-6$ & $48 \cdot 82^{d}$ & 4.05 & $44.98^{\mathrm{c}}$ & $5 \cdot 37$ & $37 \cdot 28^{a}$ & 4.40 & $43.95^{\mathrm{c}}$ & 3.49 & $40 \cdot 27^{\mathrm{b}}$ & $4 \cdot 77$ & $28 \cdot 26-57 \cdot 31$ \\
\hline $18: 3 n-6$ & $0 \cdot 85^{\mathrm{a}}$ & 0.31 & $1 \cdot 20^{\mathrm{b}}$ & 0.39 & $1 \cdot 01^{\mathrm{a}, \mathrm{b}}$ & 0.36 & $1 \cdot 13^{\mathrm{b}}$ & 0.41 & $1 \cdot 16^{\mathrm{b}}$ & 0.50 & $0.26-3.28$ \\
\hline $20: 3 n-6$ & $0.90^{\mathrm{a}}$ & 0.16 & $0.89^{a}$ & 0.11 & $0.89^{a}$ & 0.15 & $1.05^{\mathrm{b}}$ & 0.15 & $1.06^{\mathrm{b}}$ & 0.17 & $0.47-1.51$ \\
\hline $20: 4 n-6$ & $8 \cdot 49^{a, b}$ & 1.29 & $7 \cdot 68^{\mathrm{a}}$ & 1.21 & $8 \cdot 34^{a}$ & 1.55 & $9.45^{\mathrm{b}, \mathrm{c}}$ & 1.86 & $10 \cdot 51^{c}$ & 1.98 & $4.41-14.84$ \\
\hline $18: 3 n-3$ & $0.49^{\mathrm{a}}$ & 0.15 & $0.68^{\mathrm{b}}$ & 0.23 & $0.97^{c}$ & 0.31 & $0.75^{\mathrm{b}}$ & 0.16 & $0.69^{b}$ & 0.26 & $0.23-1.68$ \\
\hline $20: 5 n-3$ & $1.07^{c}$ & 0.41 & $1 \cdot 26^{\mathrm{C}}$ & 0.54 & $1 \cdot 12^{\mathrm{C}}$ & 0.40 & $0.76^{\mathrm{b}}$ & 0.20 & $0.64^{a}$ & 0.23 & $0.11-2.68$ \\
\hline $22: 6 n-3$ & $1.11^{\mathrm{C}}$ & 0.25 & $0.97^{\mathrm{a}, \mathrm{b}, \mathrm{c}}$ & 0.29 & $1.03^{b, c}$ & 0.26 & $0.93^{a, b}$ & 0.27 & $0.85^{a}$ & 0.22 & $0.33-1.89$ \\
\hline
\end{tabular}

${ }_{\mathrm{a}, \mathrm{b}, \mathrm{c}, \mathrm{d}}$ Mean values within a row with unlike superscript letters were significantly different (one-way ANOVA (in almost all cases $P<0.001, P$ values not shown) and post hoc Tukey or Kruskal-Wallis one-way ANOVA (in almost all cases $P<0 \cdot 001, P$ values not shown) and Mann-Whitney $U$ test).

* Samples with peaks under detection level were given a value of $0.005 \%(14: 1(n 20), 20: 3 n-9(n 17))$.

in this area. The intake of preformed AA may also have been comparatively high because poultry and meat contributed markedly to the PUFA intake in rural Morrumbala.

Girls living in the neighbourhoods of Quelimane consumed more wheat, sugary products, juice, oil and margarine and fewer green leafy vegetables than the rural girls (data not shown). This may be a manifestation of nutrition transition, which includes an increased consumption of processed foods, sweet beverages and edible oils ${ }^{(9,34)}$. In Quelimane, rice and maize were the most important sources of energy,

Table 5. Plasma phospholipid fatty acid compositions (\%, w/w) as well as mead (MA):arachidonic (AA) acid and AA:DHA ratios of adolescent girls ( $n$ 262) in five study areas in central Mozambique

(Mean values, standard deviations and ranges)

\begin{tabular}{|c|c|c|c|c|c|c|c|c|c|c|c|}
\hline \multirow[b]{3}{*}{ Fatty acid or fatty acid ratio } & & & \multicolumn{4}{|c|}{ Maganja da Costa } & \multicolumn{4}{|c|}{ Morrumbala } & \multirow{3}{*}{$\begin{array}{c}\text { All (n 262) } \\
\text { Range }\end{array}$} \\
\hline & \multicolumn{2}{|c|}{$\begin{array}{l}\text { Quelimane } \\
\qquad(n 83)\end{array}$} & \multicolumn{2}{|c|}{$\begin{array}{l}\text { District town } \\
\quad(n 18)\end{array}$} & \multicolumn{2}{|c|}{$\begin{array}{l}\text { Rural villages } \\
\qquad(n 73)\end{array}$} & \multicolumn{2}{|c|}{$\begin{array}{l}\text { District town } \\
\quad(n 22)\end{array}$} & \multicolumn{2}{|c|}{$\begin{array}{l}\text { Rural villages } \\
\qquad(n 66)\end{array}$} & \\
\hline & Mean & SD & Mean & SD & Mean & SD & Mean & SD & Mean & SD & \\
\hline $12: 0$ & $0.05^{\mathrm{c} *}$ & 0.03 & $0.07^{d}$ & 0.03 & $0.06^{d}$ & 0.03 & $0.03^{b}$ & 0.01 & $0.02^{a}$ & 0.01 & $0.005^{*}-0.18$ \\
\hline $14: 0$ & $0.55^{\mathrm{c}}$ & 0.19 & $0.75^{d}$ & 0.22 & $0.68^{\mathrm{d}}$ & 0.20 & $0.42^{\mathrm{b}}$ & 0.11 & $0.33^{\mathrm{a}}$ & 0.07 & $0.20-1.42$ \\
\hline $16: 0$ & $32 \cdot 05^{\mathrm{b}}$ & 1.42 & $31 \cdot 30^{\mathrm{a}, \mathrm{b}}$ & $1 \cdot 12$ & $32 \cdot 46^{\mathrm{c}}$ & 1.55 & $31.37^{\mathrm{a}}$ & 1.44 & $31 \cdot 13^{\mathrm{a}}$ & 1.81 & $28.04-37.84$ \\
\hline $17: 0$ & $0.37^{\mathrm{a}}$ & 0.07 & $0.39^{a}$ & 0.07 & $0.40^{\mathrm{a}}$ & 0.07 & $0.46^{\mathrm{b}}$ & 0.07 & $0.58^{\mathrm{c}}$ & 0.09 & $0.22-0.84$ \\
\hline $18: 0$ & $14 \cdot 17^{\mathrm{a}}$ & 1.24 & $14.48^{\mathrm{a}, \mathrm{b}}$ & $1 \cdot 18$ & $13.98^{\mathrm{a}}$ & 1.37 & $14 \cdot 52^{\mathrm{a}, \mathrm{b}}$ & 1.27 & $14.94^{\mathrm{b}}$ & 1.53 & $9.97-17.84$ \\
\hline $16: 1 n-7$ & $0.47^{\mathrm{a}}$ & 0.17 & $0.68^{\mathrm{b}}$ & 0.23 & $1.05^{\mathrm{d}}$ & 0.33 & $0.75^{\mathrm{b}, \mathrm{c}}$ & 0.20 & $0.82^{c}$ & 0.24 & $0.18-2.33$ \\
\hline $18: 1 n-9$ & $9 \cdot 66^{\mathrm{a}}$ & $1 \cdot 13$ & $10 \cdot 92^{c}$ & $1 \cdot 13$ & $12.67^{d}$ & 1.95 & $10 \cdot 64^{\mathrm{b}, \mathrm{c}}$ & 1.09 & $11 \cdot 31^{\mathrm{c}}$ & 1.82 & $7.40-18.13$ \\
\hline $20: 3 n-9$ & $0 \cdot 19^{a}$ & 0.09 & $0.36^{b, c}$ & 0.17 & $0.60^{d}$ & 0.32 & $0.30^{\mathrm{b}}$ & 0.12 & $0.46^{\mathrm{c}}$ & 0.28 & $0.005^{*}-1.52$ \\
\hline $18: 2 n-6$ & $18 \cdot 74^{\mathrm{C}}$ & $2 \cdot 37$ & $18 \cdot 44^{\mathrm{b}, \mathrm{c}}$ & 3.09 & $14.93^{\mathrm{a}}$ & $2 \cdot 13$ & $17 \cdot 00^{\mathrm{b}}$ & $2 \cdot 30$ & $15 \cdot 21^{\mathrm{a}}$ & 1.99 & $10 \cdot 27-24 \cdot 68$ \\
\hline $18: 3 n-6$ & $0.06^{\mathrm{a}}$ & 0.05 & $0.13^{\mathrm{b}, \mathrm{c}}$ & 0.05 & $0 \cdot 11^{\mathrm{b}}$ & 0.04 & $0 \cdot 12^{\mathrm{b}, \mathrm{c}}$ & 0.05 & $0.14^{c}$ & 0.05 & $0.005^{\star}-0.36$ \\
\hline $20: 3 n-6$ & $3.67^{a}$ & 0.73 & $3 \cdot 66^{\mathrm{a}}$ & 0.49 & $3.55^{a}$ & 0.60 & $4 \cdot 25^{b}$ & 0.48 & $4 \cdot 23^{\mathrm{b}}$ & 0.70 & $1.92-5 \cdot 84$ \\
\hline $20: 4 n-6$ & $10 \cdot 92^{\mathrm{a}}$ & 1.25 & $10 \cdot 15^{a}$ & 1.24 & $10 \cdot 85^{a}$ & 1.58 & $12 \cdot 15^{\mathrm{b}}$ & 1.64 & $13 \cdot 50^{c}$ & $2 \cdot 11$ & $6.93-18.49$ \\
\hline $22: 4 n-6$ & $0.47^{\mathrm{a}}$ & 0.09 & $0.48^{\mathrm{a}}$ & $0 \cdot 10$ & $0.57^{\mathrm{b}}$ & 0.12 & $0.64^{\mathrm{c}}$ & 0.11 & $0.81^{d}$ & 0.14 & $0.005^{*}-1.30$ \\
\hline $18: 3 n-3$ & $0 \cdot 13^{a}$ & 0.05 & $0.15^{b}$ & 0.04 & $0 \cdot 24^{c}$ & 0.11 & $0 \cdot 18^{b}$ & 0.07 & $0 \cdot 17^{b}$ & 0.07 & $0.005^{*}-0.61$ \\
\hline $20: 5 n-3$ & $1.04^{c}$ & 0.39 & $1 \cdot 27^{\mathrm{c}}$ & 0.48 & $1.06^{\mathrm{c}}$ & 0.36 & $0.77^{\mathrm{b}}$ & 0.20 & $0.61^{\mathrm{a}}$ & 0.21 & $0.16-2 \cdot 62$ \\
\hline $22: 5 n-3$ & $1 \cdot 13^{b}$ & 0.23 & $1 \cdot 11^{\mathrm{a}, \mathrm{b}}$ & 0.31 & $1.00^{\mathrm{a}}$ & 0.22 & $1 \cdot 10^{a, b}$ & 0.28 & $1.03^{a, b}$ & 0.22 & $0.41-1.75$ \\
\hline $22: 6 n-3$ & $6 \cdot 34^{\mathrm{C}}$ & $1 \cdot 17$ & $5 \cdot 66^{\mathrm{b}, \mathrm{c}}$ & 1.38 & $5 \cdot 78^{\mathrm{b}}$ & 1.25 & $5 \cdot 2^{a, b}$ & $1 \cdot 23$ & $4 \cdot 72^{\mathrm{a}}$ & 1.02 & $2 \cdot 21-10 \cdot 19$ \\
\hline $20: 3 n-9: 20: 4 n-6$ (MA:AA) & $0.019^{a}$ & 0.009 & $0.036^{c}$ & 0.018 & $0.059^{d}$ & 0.039 & $0.026^{\mathrm{b}}$ & 0.013 & $0.037^{b, c}$ & 0.031 & $0.007-0.192$ \\
\hline $20: 4 n-6: 22: 6 n-3$ (AA:DHA) & $1 \cdot 78^{\mathrm{a}}$ & 0.37 & $1.87^{a, b}$ & 0.39 & $1.94^{\mathrm{b}}$ & 0.39 & $2 \cdot 38^{\mathrm{C}}$ & 0.46 & $2.98^{d}$ & 0.70 & $1 \cdot 16-5 \cdot 98$ \\
\hline
\end{tabular}

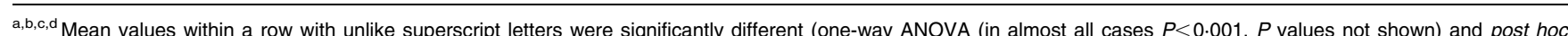
Tukey or Kruskal-Wallis one-way ANOVA (in almost all cases $P<0.001, P$ values not shown) and Mann-Whitney $U$ test).

* Samples with peaks under detection level were given a value of $0.005 \%(12: 0(n 2), 20: 3 n-9(n 2), 18: 3 n-6(n 29), 22: 4 n-6(n 1), 18: 3 n-3(n 1))$. 
and PUFA-rich soyabean oil was an important source of fat. Consequently, the absolute intake of LA and the proportions of LA in serum lipids were higher than those in the rural areas. The intake of $n-3$ LC-PUFA was also higher in Quelimane than in the rural areas, and this was reflected in a high proportion of $n-3$ LC-PUFA in serum lipids. The results indicate that LA did not markedly disturb $n$-3 LC-PUFA incorporation.

There are studies that have focused on the serum or erythrocyte fatty acid compositions of some population groups in eastern Africa (e.g. Mahomed et al. ${ }^{(35)}$, Knoll et al. ${ }^{(36)}$ and Kuipers et $a l{ }^{(37)}$ ). We are, however, not aware of comparable serum cholesteryl ester or phospholipid fatty acid data on adolescent girls in Africa. One recent study reports marked differences between serum cholesteryl ester fatty acid compositions of adult men and women from five Tanzanian ethnic groups ${ }^{(38)}$. In that study, the diet of the inhabitants of the Island of Chole had similarities (the consumption of coconut, fish and fruit) with the diet of the girls in the Maganja da Costa region in the present study. The serum cholesteryl ester fatty acid composition of adult Chole islanders was also quite similar to the corresponding fatty acid composition of the girls living in rural Maganja da Costa ${ }^{(38)}$.

The serum phospholipid fatty acid composition of adolescent Swedish girls has been analysed in the same laboratory as our samples ${ }^{(39)}$. Compared to those results, the mean proportions of LA in the present study (14.9-18.7\%) were markedly lower than those in the Swedish study (22.7\%). The mean proportions of ALA $(0 \cdot 13-0 \cdot 24 \%)$ and EPA $(0.61-1.27 \%)$ in our data were fairly comparable to those reported in the Swedish girls $(0.23$ and $1.04 \%$ for ALA and EPA, respectively). However, the proportions of AA (10.2-13.5\%) and DHA (4.7-6.3\%) were clearly higher in the present study than in the Swedish data ( 9.2 and $4.0 \%$ for AA and DHA, respectively) ${ }^{(39)}$. A study of normal-weight American adolescent boys and girls ${ }^{(40)}$ reported mean LA, ALA, AA, EPA and DHA proportions in serum phospholipids to be $24 \cdot 7,0 \cdot 20,10 \cdot 6,0.43$ and $2.28 \%$, respectively, which indicates that those subjects had a higher proportion of LA and lower proportions of EPA and DHA than those in the present study. These comparisons suggest that the low intakes of fat and PUFA by adolescent Mozambican girls do not compromise AA status and even possibly enhance DHA status in comparison to Western adolescents. One explanation for this could be the low total fat intake in the present study. Intervention studies ${ }^{(41,42)}$ have shown that low-fat diets increase the proportion of AA and DHA in phospholipids as compared to moderate- or high-fat diets, apparently because of increased desaturase activity. Furthermore, low PUFA intake may enhance DHA synthesis from $\mathrm{ALA}^{(43)}$. In mouse experiments, the maximal accumulation of DHA in phospholipids was achieved with LA + ALA intakes that were smaller than $3 \mathrm{en} \%{ }^{(43)}$. Genetic polymorphisms of fatty acid metabolising enzymes may also explain part of the differences between Mozambican and Western adolescents. African populations have high frequencies of a fatty acid desaturase gene variant that favours LC-PUFA synthesis ${ }^{(44)}$

The rural-urban differences in the dietary fat sources and serum fatty acid compositions may reflect an ongoing transition from low-fat, low-LA diets to higher intakes of fat and LA. Although the current EFA status seems to be fairly good, the situation may change in the future. Increased use of high-LA vegetable oils, such as sunflower oil, may undermine the balance between $n-6$ and $n-3$ fatty acids. Soyabean oil, although not ideal as a source of ALA, would be a better alternative than high-LA oils, which are poor in $\mathrm{ALA}^{(8)}$. Furthermore, it would be important to maintain or increase the intake of fish and shellfish, because they are significant sources of $n$-3 LC-PUFA. Green leafy vegetables could be a valuable source of ALA ${ }^{(32)}$.

A limitation of the present study is that the cross-sectional data were collected only at the end of the lean season, when the intake of PUFA-rich foods like groundnuts was lower than it was during the harvest season (L Korkalo, personal communication). Thus, the conclusions cannot be extended for the entire year. Energy and nutrient intake was assessed by a single $24 \mathrm{~h}$ dietary recall, which does not allow us to draw conclusions at the individual level. Because the number of participants from district towns was small, the results on dietary intake among those girls should be interpreted with caution. It is challenging to measure fatty acid intake in Mozambique where, e.g., vegetable oils are sold in small, unlabelled batches in the marketplaces. The girls did not necessarily know what kind of oil (such as palm oil or soyabean oil) they had consumed. Furthermore, we relied on published fatty acid composition values of some key foods, such as mango. The girls were not requested to fast before blood sampling, because this was considered unfeasible. However, the fact that serum cholesteryl ester and phospholipid fractions were used in the fatty acid composition analyses diminishes the possible impact of recent meals on the results.

In conclusion, dietary intakes and serum proportions of EFA differ between adolescent girls living in different communities in central Mozambique. No biochemical EFA insufficiency is indicated, and LC-PUFA proportions in the serum phospholipids of Mozambican girls are good in comparison with Western adolescents. The rural-urban differences in fat sources and serum fatty acid compositions may reflect an ongoing transition from a low-fat, low-LA diet to higher intakes of fat and LA. More studies are needed to evaluate how nutrition transition modifies serum fatty acid compositions in different population groups in Mozambique and elsewhere in sub-Saharan Africa.

\section{Acknowledgements}

We express our gratitude to the girls who participated in the present study. We also thank all of the members of the fieldwork staff who made the study successful.

The study was supported by the Academy of Finland (decision number 127828) and the Embassy of Finland, Maputo. L. K. received funding from the Finnish Graduate School on Applied Bioscience: Bioengineering, Food \& Nutrition, Environment (ABS).

The authors' responsibilities were as follows: M. M., L. K. and R. F. designed the study; M. M., L. K., R. F., H. H. and 
K. S. coordinated and conducted the study in the field; S. T. was responsible for the fatty acid analyses; E. M. V., R. F. and $\mathrm{H}$. H. processed the data and carried out statistical analyses; M. M., B. V. and R. F. planned the manuscript; R. F. and M. M. wrote the paper; and R. F. had primary responsibility for final content. All authors read and approved the final manuscript.

None of the authors declared a conflict of interest.

\section{References}

1. Hodson L, Skeaff CM \& Fielding BA (2008) Fatty acid composition of adipose tissue and blood in humans and its use as a biomarker of dietary intake. Prog Lipid Res 47, 348-380.

2. Abbott SK, Else PL \& Hulbert AJ (2010) Membrane fatty acid composition of rat skeletal muscle is most responsive to the balance of dietary $n-3$ and $n-6$ PUFA. Br J Nutr 103, 522-529.

3. Lattka E, Klopp N, Demmelmair H, et al. (2012) Genetic variations in polyunsaturated fatty acid metabolism - implications for child health? Ann Nutr Metab 60, Suppl. 3, 8-17.

4. Ratnayake WM \& Galli C (2009) Fat and fatty acid terminology, methods of analysis and fat digestion and metabolism: a background review paper. Ann Nutr Metab 55, 8-43.

5. Jeppesen PB, Høy CE \& Mortensen PB (2000) Deficiencies of essential fatty acids, vitamin $\mathrm{A}$ and $\mathrm{E}$ and changes in plasma lipoproteins in patients with reduced fat absorption or intestinal failure. Eur J Clin Nutr 54, 632-642.

6. Crompton DW \& Nesheim MC (2002) Nutritional impact of intestinal helminthiasis during the human life cycle. Annu Rev Nutr 22, 35-59.

7. Briend A, Dewey KG \& Reinhart GA (2011) Fatty acid status in early life in low-income countries - overview of the situation, policy and research priorities. Matern Child Nutr 7, Suppl. 2, 141-148.

8. Michaelsen KF, Dewey KG, Perez-Exposito AB, et al. (2011) Food sources and intake of $n-6$ and $n-3$ fatty acids in low-income countries with emphasis on infants, young children (6-24 months), and pregnant and lactating women. Matern Child Nutr 7, Suppl. 2, 124-140.

9. Popkin BM, Adair LS \& Ng SW (2012) Global nutrition transition and the pandemic of obesity in developing countries. Nutr Rev 70, 3-21.

10. MacIntyre UE, Kruger HS, Venter CS, et al. (2002) Dietary intakes of an African population in different stages of transition in the North West Province, South Africa: The THUSA Study. Nutr Res 22, 239-256.

11. Keding GB, Msuya JM, Maass BL, et al. (2011) Dietary patterns and nutritional health of women: the nutrition transition in rural Tanzania. Food Nutr Bull 32, 218-226.

12. Steyn NP, Nel JH, Parker WA, et al. (2011) Dietary, social, and environmental determinants of obesity in Kenyan women. Scand J Public Health 39, 88-97.

13. Steyn NP, Nel JH, Parker W, et al. (2012) Urbanisation and the nutrition transition: a comparison of diet and weight status of South African and Kenyan women. Scand J Public Health 40, 229-238.

14. Abrahams Z, McHiza Z \& Steyn NP (2011) Diet and mortality rates in Sub-Saharan Africa: stages in the nutrition transition. BMC Public Health 11, 801.

15. Korkalo L, Freese R, Fidalgo L, et al. (2014) A cross-sectional study on diet and nutritional status of adolescent girls in Zambézia Province, Mozambique (the ZANE Study): design, methods, and study population characteristics. JMIR Res Protoc 3, e12.
16. Korkalo L, Hauta-alus H \& Mutanen M (2013) Food Composition Tables for Mozambique: Version 2, October 2011. http://www.helsinki.fi/food-and-environment/research/groups/ nutrition_research.html (accessed January 2015).

17. Nutrition Surveys and Calculations (2010) Guidelines, Software and Additional Information. Last page modification: 2 April 2010. http://www.nutrisurvey.de (accessed January 2015).

18. World Health Organization (1995) Physical Status: The Use and Interpretation of Anthropometry. Report of a WHO Expert Committee. WHO Technical Report Series no. 854. Geneva: WHO.

19. World Health Organization (2013) Growth Reference for 5-19 Years. Application Tools. http://www.who.int/growth ref/tools/en/ (accessed January 2015).

20. de Onis M, Onyango AW, Borghi E, et al. (2007) Development of a WHO growth reference for school-aged children and adolescents. Bull World Health Organ 85, 660-667.

21. Boberg M, Croon LB, Gustafsson IB, et al. (1985) Platelet fatty acid composition in relation to fatty acid composition in plasma and to serum lipoprotein lipids in healthy subjects with special reference to the linoleic acid pathway. Clin Sci (Lond) 68, 581-587.

22. Holman RT (1960) The ratio of trienoic:tetraenoic acids in tissue lipids as a measure of essential fatty acid requirement. J Nutr 70, 405-410.

23. Holman RT, Smythe L \& Johnson S (1979) Effect of sex and age on fatty acid composition of human serum lipids. $A m \mathrm{~J}$ Clin Nutr 32, 2390-2399.

24. Jeppesen PB, Christensen MS, Høy CE, et al. (1997) Essential fatty acid deficiency in patients with severe fat malabsorption. Am J Clin Nutr 65, 837-843.

25. Jeppesen PB, Høy CE \& Mortensen PB (1998) Essential fatty acid deficiency in patients receiving home parenteral nutrition. Am J Clin Nutr 68, 126-133.

26. Al MD, van Houwelingen AC, Kester AD, et al. (1995) Maternal essential fatty acid patterns during normal pregnancy and their relationship to the neonatal essential fatty acid status. Br J Nutr 74, 55-68.

27. Otto SJ, Houwelingen AC, Antal M, et al. (1997) Maternal and neonatal essential fatty acid status in phospholipids: an international comparative study. Eur J Clin Nutr 51, 232-242.

28. Krebs-Smith SM, Kott PS \& Guenther PM (1989) Mean proportion and population proportion: two answers to the same question? J Am Diet Assoc 89, 671-676.

29. Food and Agriculture Organization of the United Nations (2010) Fats and Fatty Acids in Human Nutrition. Report of an Expert Consultation. FAO Food and Nutrition Paper no. 91. Rome: FAO.

30. Hsiao LL, Howard RJ, Aikawa M, et al. (1991) Modification of host cell membrane lipid composition by the intraerythrocytic human malaria parasite Plasmodium falciparum. Biochem J 274, 121-132.

31. Guesnet P, Lallemand SM, Alessandri JM, et al. (2011) $\alpha$-Linolenate reduces the dietary requirement for linoleate in the growing rat. Prostaglandins Leukot Essent Fatty Acids 85, 353-360.

32. van der Walt AM, Ibrahim MI, Bezuidenhout CC, et al. (2009) Linolenic acid and folate in wild-growing African dark leafy vegetables (morogo). Public Health Nutr 12, 525-530.

33. Gibson RA, Muhlhausler B \& Makrides M (2011) Conversion of linoleic acid and $\alpha$-linolenic acid to long-chain polyunsaturated fatty acids (LCPUFAs), with a focus on pregnancy, lactation and the first 2 years of life. Matern Child Nutr 7, Suppl. 2, 17-26.

34. Vorster HH, Kruger A \& Margetts BM (2011) The nutrition transition in Africa: can it be steered into a more positive direction? Nutrients 3, 429-441. 
35. Mahomed K, Williams MA, King IB, et al. (2007) Erythrocyte omega-3, omega- 6 and trans fatty acids in relation to risk of preeclampsia among women delivering at Harare Maternity Hospital, Zimbabwe. Physiol Res 56, 37-50.

36. Knoll N, Kuhnt K, Kyallo FM, et al. (2011) High content of long-chain $n-3$ polyunsaturated fatty acids in red blood cells of Kenyan Maasai despite low dietary intake. Lipids Health Dis 10, 141.

37. Kuipers RS, Luxwolda MF, Sango WS, et al. (2011) Postdelivery changes in maternal and infant erythrocyte fatty acids in 3 populations differing in fresh water fish intakes. Prostaglandins Leukot Essent Fatty Acids 85, 387-397.

38. Ruiz-Núñez B, Kuipers RS, Luxwolda MF, et al. (2014) Saturated fatty acid (SFA) status and SFA intake exhibit different relations with serum total cholesterol and lipoprotein cholesterol: a mechanistic explanation centered around lifestyle-induced low-grade inflammation. J Nutr Biochem 25, 304-312.

39. Swenne I, Rosling A, Tengblad S, et al. (2011) Essential fatty acid status in teenage girls with eating disorders and weight loss. Acta Paediatr 100, 762-767.
40. Steffen LM, Vessby B, Jacobs DR Jr, et al. (2008) Serum phospholipid and cholesteryl ester fatty acids and estimated desaturase activities are related to overweight and cardiovascular risk factors in adolescents. Int J Obes (Lond) 32, 1297-1304.

41. Raatz SK, Bibus D, Thomas W, et al. (2001) Total fat intake modifies plasma fatty acid composition in humans. $J$ Nutr 131, 231-234.

42. Raatz SK, Young LR, Picklo MJ Sr, et al. (2012) Total dietary fat and fatty acid content modifies plasma phospholipid fatty acids, desaturase activity indices, and urinary prostaglandin $\mathrm{E}$ in women. Nutr Res 32, 1-7.

43. Gibson RA, Neumann MA, Lien EL, et al. (2013) Docosahexaenoic acid synthesis from $\alpha$-linolenic acid is inhibited by diets high in polyunsaturated fatty acids. Prostaglandins Leukot Essent Fatty Acids 88, 139-146.

44. Sergeant S, Hugenschmidt CE, Rudock ME, et al. (2012) Differences in arachidonic acid levels and fatty acid desaturase (FADS) gene variants in African Americans and European Americans with diabetes or the metabolic syndrome. Br J Nutr 107, $547-555$. 